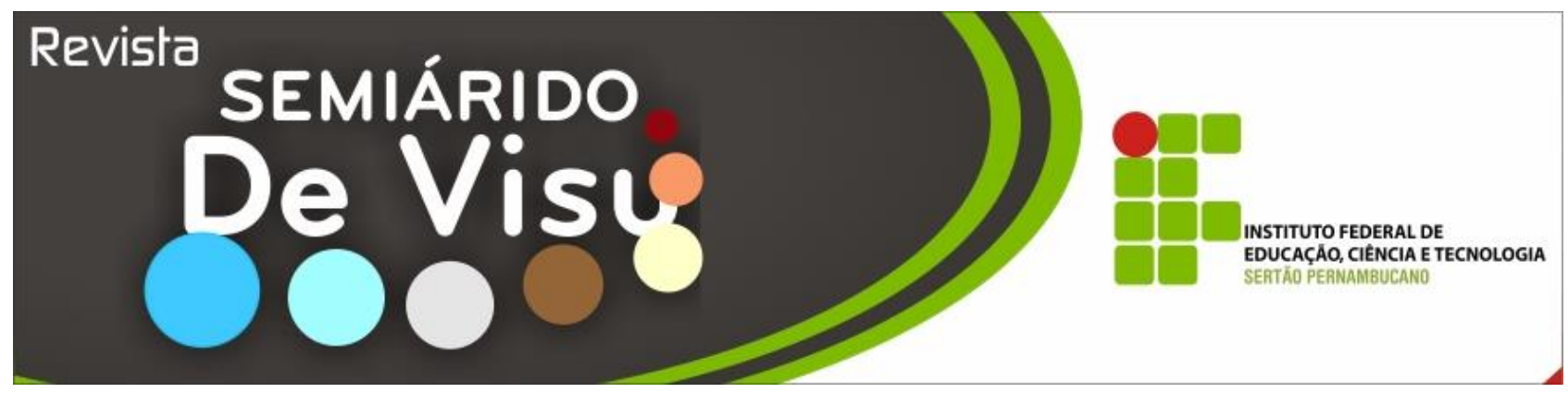

\title{
O agronegócio vitivinícola sob a ótica das indicações geográficas da União Europeia (UE)
}

\author{
Rosemary Barbosa de Melo $^{1}$, Reney Dorow ${ }^{2}$, Sylvan Martins dos Reis ${ }^{3}$, Marília Zabot ${ }^{4}$, Thiago \\ Borges Feitosa ${ }^{5}$
}

\footnotetext{
${ }^{1}$ IF Sertão PE, Rodovia BR 235, Km 22, Projeto Senador Nilo Coelho - N4, CEP: 56300-000 | Petrolina/PE - Brasil, Fone: (87) 2101-8050, e-mail: rosemarybm1 @ hotmail.com

${ }^{2}$ Empresa de Pesquisa Agropecuária e Extensão Rural de Santa Catarina ( EPAGRI), Rodovia Admar Gonzaga, 1.347, Itacorubi, Caixa Postal 502 88034-901 Florianópolis, SC, Brasil Fone: (48)3665-5000, fax: (48)3665-5010 e-mail: reney@epagri.sc.gov.br

${ }^{3}$ e 4 Universidade Federal do Rio Grande do Sul/Cepan, Av. Bento Gonçalves, 7712 - CEP 91540-000 - Porto Alegre - RS - Brasil, Fone : 5551 3308.6586, e-mail: cepan@ufrgs.br

${ }^{5}$ Universidade Federal do Vale do São Francisco, Av. José de Sá Maniçoba, s/n - Centro CEP 56304-917, Petrolina-PE Fone: (87) 21016705 , Fax:(87) 21016830.
}

RESUMO: O presente trabalho tem como objetivo analisar as Indicações Geográficas e sua importância, descrevendo o Mercado Mundial de Vinhos, e seu uso na União Europeia. A pesquisa é bibliográfica de caráter qualitativo e quantitativo. Foram consultados os bancos de dados da FAO, da Wine Institute e Comissão Europeia. Além disso, foram utilizados artigos científicos, livros e revistas que tratam sobre o tema pesquisado. Concluiu-se que mundialmente o número de Indicações Geográficas é de 3.048, só na União Europeia há 1.991, o que corresponde a $63 \%$ do total no mercado global de IG's. Sendo 1.134 DOP, representando 69\% do total das IG's da União Europeia. Dessas IG's, 49\% estão nos países França, Itália, Espanha e Portugal. Quanto as IGP's existem 587, o que corresponde a 31\%, também estão centralizadas nos países citados anteriormente. Portanto, as IG's têm sido um instrumento inovador e fundamental na redução da assimetria de informação e aproximação entre produtores e consumidores de vinhos na União Europeia.

Palavras-chave: consumidor, certificação, assimetria de informação

\section{The viticulture agribusiness under the optics of geographical indications of the European Union (EU)}

\begin{abstract}
The present work aims to analyze the Geographical Indications and their importance, describing the World Wine Market and its use in the European Union. The research is bibliographical of qualitative and quantitative character. The FAO, Wine Institute and European Commission databases were consulted. In addition, scientific articles, books and journals dealing with the researched topic were used. It was concluded that worldwide the number of Geographical Indications is 3,048, in the European Union alone there are 1,991, corresponding to $63 \%$ of the total in the global market of GIs. Being 1,134 PDOs, representing 69\% of the total GIs of the European Union. Of these GIs, 49\% are in France, Italy, Spain and Portugal. Regarding IGPs there are 587, which corresponds to 31\%, are also centralized in the countries mentioned above. Therefore, GIs have been an innovative and fundamental instrument in reducing information asymmetry and approximation between wine producers and consumers in the European Union.
\end{abstract}

keywords: consumer, certification, information asymmetry 
(MELO et al., 2017)

\section{Introdução}

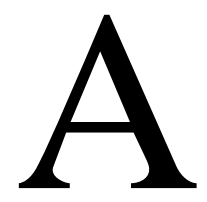

oferta de diferenciais de qualidade ao mercado é carregada de dificuldades relativas à assimetria de informação, isso ocorre quando os produtores não produzem um sinal que distingue a qualidade dos seus produtos e por sua vez os consumidores baseiam suas escolhas na qualidade média percebida no mercado. É nesse contexto que, cada vez mais, empresas de todos os tamanhos estão buscando alcançar níveis elevados de diferenciação, e para isso investem em qualidade, produtividade e em inovações. Uma das inovações mais significativas no mercado agroalimentar, no campo da diferenciação competitiva, são os registros de indicação geográfica. Essas, por sua vez, podem minimizar os problemas decorrentes da assimetria de informação, agregando fatores intrínsecos e extrínsecos relativos à qualidade percebida pelo consumidor.

No atual cenário econômico, observa-se a transição de um paradigma de relativa estabilidade, comum no modelo de produção em massa, para um ambiente dominado pelas exigências cada vez maiores dos consumidores por produtos diferenciados e com ciclo de vida cada vez menor. Neste estudo, destacamos o potencial do registro de Indicação Geográfica por meio de uma análise preliminar de sua aplicação ao agronegócio vitivinícola.

A Indicação Geográfica transmite ao longo da cadeia de valor e especialmente ao consumidor final, as informações necessárias sobre a origem, território e a qualidade dos produtos a ele associados. No que se refere ao agronegócio vitivinícola, a temática da indicação geográfica está alicerçada no direito de propriedade intelectual, bastante discutido e aplicado em regiões vitivinícolas da Europa e dos Estados Unidos. No Brasil, temos indicações geográficas relativos a produção de vinho mais recentes, com destaque para as Indicações de Procedência: Vale dos Vinhedos/RS, Pinto Bandeira/RS, Altos Montes/RS, Região de Monte Belo/RS, Farroupilha/RS e Vales da Uva Goethe/SC; e uma Denominação de Origem: Vale dos
Vinhedos/RS. Devemos destacar ainda que os países europeus, tais como França, Espanha, Itália e Portugal, são referências mundiais em vinhos finos e que as suas formas de organização em clusters, também conhecidos como distritos industriais e redes de empresas, têm contribuído para inovações no setor vinícola. Outras regiões conhecidas como "o novo mundo do vinho" - Nova Zelândia, África do Sul, Califórnia, Chile e Argentina, também se destacam no mercado internacional por apresentarem estratégias e inovações, dentre elas as indicações geográficas (COCCO et al., 1999).

Desse modo, conforme ressalta Llopis (1997), o panorama vitivinícola mundial revela que os países que adotam a Indicação Geográfica como diferencial distintivo são aqueles que se preocupam em produzir vinhos de qualidade, amparados por legislações específicas.

Os potenciais oferecidos pelo uso de Indicações Geográficas têm estimulado as regiões produtoras de vinhos a inovarem nos seus processos de produção, estratégias de marketing e, como consequência, tem promovido o desenvolvimento regional e vem contribuindo para o desempenho vitivinícola nas diferentes regiões onde ele se expressa.

A produção mundial de vinhos é significativa ultrapassando 30 milhões de toneladas, segundo a FAO em 2014 com destaque para os países da União Europeia. A União Europeia ocupa um lugar de grande importância tanto na produção, como nas exportações mundiais de vinho, sem responsável em 2014 por cerca de 60\% do comércio internacional de vinho.

Dada a importância da União Europeia no agronegócio vitivinícola mundial, este estudo visou analisar a participação deste bloco econômico no registro de IG's. Considera-se que as Indicações geográficas representam um diferencial e corresponde uma oportunidade de agregar valor ao vinho, por meio da promoção territorial, identidade de produção, terroir, dentre outros aspectos.

\section{Aspectos conceituais das indicações geográficas}


(MELO et al., 2017)

Em 1994, a Organização Mundial do Comércio (OMC) reconheceu o conceito de Indicação Geográfica. Em seu acordo TradeRelated Aspects of Intellectual Property Rights (TRIPs), seção 3 (IG), artigos 22 a 24, a OMC define indicações geográficas como "indicações as quais identifiquem um produto como originário de um território de paísmembro ou região ou localidade nesse território, quando uma dada qualidade, reputação ou outra característica deste produto é essencialmente atribuída a sua origem geográfica" (GOLLO, 2006).

Como vimos, a Indicação Geográfica tem sua definição estabelecida no Acordo TRIPS, o qual inclui também as denominações de origem. Antes deste Acordo, existia o Acordo de Lisboa, assinado em 1958, segundo o qual os limites de denominações de origem contemplavam critérios de qualidade e características de um produto atribuíveis à sua origem geográfica. O Acordo TRIPS incorpora a novidade de também mencionar a reputação do produto. A definição de IG no Acordo TRIPS, no entanto, não abrange todas as indicações de procedência, porque o produto identificado com uma IG não deve apenas ser originário de um local geográfico específico, mas também deve ter uma qualidade, reputação ou outra que é essencialmente atribuível à sua origem geográfica; nem todas as indicações de procedência cumprem estes requisitos. Após seu reconhecimento como uma forma distinta de direitos de propriedade intelectual no acordo TRIPS, IGs também têm recebido atenção internacional significativa fora da União Europeia (MOSCHINI, 2004).

Segundo Addor \& Grazioli (2002) a classificação das IGs se dá de maneira estruturada em:

\section{a) Indicação de Procedência}

A Indicação de Procedência (IP) se refere a qualquer expressão ou sinal utilizado para indicar que um produto ou um serviço originário de um país, região ou um lugar específico, sem qualquer elemento de qualidade ou reputação. Complementa ainda que Indicações de Procedência se relacionam com a área geográfica de onde o produto é originário, e não há outro tipo de origem, como o fabricante do produto, como é o caso de marcas. A definição de indicações de procedência não implica qualquer atributo de qualidade, característica ou reputação do produto identificado atribuído ao seu lugar de origem.

\section{b) Denominação de Origem}

As Denominações de Origem não se originam somente a partir de um lugar específico, mas devem, além disso, agregar a qualidade e características que são devidas exclusiva ou essencialmente ao meio geográfico, incluindo aspectos naturais e fatores humanos, de onde o produto é originário. Assemelha-se a IP, mas a definição de denominação de origem tem requisitos mais elevados em relação aos seguintes aspectos: a) para as denominações de origem, "reputação" mera do produto não é suficiente para obter a proteção de uma denominação de origem; qualidades específicas ou características devem se expressar no produto particular; b) as denominações de origem devem ter nomes geográficos dos países, regiões ou localidades; meros símbolos ou emblemas evocando indiretamente origem geográfica não são suficientes.

Após esses avanços regulatórios, por seu valor econômico, os produtos de regiões com denominações específicas são recorrentemente peças de destaque e de disputa nos organismos que regulam o comércio internacional (CALDAS et al., 2005).

\section{Material e métodos}

A pesquisa é bibliográfica e caráter qualitativo e quantitativo, através da apresentação de dados estatísticos sobre a participação do bloco econômico, União Europeia nas IG's mundiais. Foram consultados os bancos de dados da FAO, da Wine Institute e Comissão Europeia. Além disso, foram utilizados artigos científicos, livros e revistas que tratam sobre o tema pesquisado. Primeiramente os estudos foram realizados via 
(MELO et al., 2017)

artigos científicos e em seguida foram analisados os bancos de dados mencionados acima.

\section{Resultados e discussão}

\section{a. Mercado Mundial de Vinhos}

A produção mundial de vinhos, em 2014, segundo a FAO, foi de 30,8 milhões de toneladas, com destaque para os países da União Europeia: Itália, França, Espanha e Portugal, que estão entre os dez maiores produtores mundiais (Tabela 1). Entretanto, novos países despontam como proeminentes produtores de vinhos, provando que não é somente nos antigos e conhecidos terroirs europeus que se fazem vinhos de qualidade. Esta abertura fez com que aumentasse o número de países produtores, os chamados países do "novo mundo vinícola" com a contribuição do Hemisfério Sul, essencialmente Chile, África do Sul e Austrália, que junto com os EUA têm marcado a produção mundial com volumes importantes destinados aos mercados externos.

Tabela 01 - Produção Mundial de Vinhos em toneladas.

\begin{tabular}{|l|c|c|c|c|c|}
\hline Países & $\mathbf{2 0 0 6}$ & $\mathbf{2 0 0 8}$ & $\mathbf{2 0 1 0}$ & $\mathbf{2 0 1 2}$ & $\mathbf{2 0 1 4}$ \\
\hline França & 5.349 .330 & 4.268 .900 & 4.541 .820 & 4.293 .466 & 4.209 .724 \\
\hline Itália & 4.963 .300 & 4.609 .550 & 4.580 .000 & 4.796 .600 & 3.826 .531 \\
\hline Espanha & 3.890 .730 & 3.736 .690 & 3.610 .000 & 4.607 .850 & 3.112 .260 \\
\hline USA & 2.360 .000 & 2.530 .000 & 2.211 .300 & 3.300 .000 & 2.987 .000 \\
\hline China & 1.400 .000 & 1.500 .000 & 1.657 .500 & 1.700 .000 & 1.650 .000 \\
\hline Chile & 802.441 & 868.297 & 915.238 & 1.214 .000 & 1.255 .371 \\
\hline Austrália & 1.429 .790 & 1.244 .780 & 1.133 .860 & 1.186 .343 & 1.225 .919 \\
\hline Argentina & 1.539 .600 & 1.467 .640 & 1.625 .080 & 1.498 .380 & 1.166 .025 \\
\hline África do Sul & 939.779 & 1.016 .480 & 921.700 & 1.146 .006 & 1.056 .841 \\
\hline Portugal & 733.784 & 547.962 & 694.612 & 603.327 & 617.780 \\
\hline Total Mundial & $\mathbf{2 8 . 5 8 4 . 2 4 8}$ & $\mathbf{2 7 . 4 4 9 . 4 1 2}$ & $\mathbf{2 5 . 6 3 6 . 0 4 3}$ & $\mathbf{2 7 . 6 7 6 . 7 2 8}$ & $\mathbf{3 0 . 8 0 5 . 8 4 3}$ \\
\hline Participação dos 10 maiores produtores & $\mathbf{8 2 \%}$ & $\mathbf{7 9 \%}$ & $\mathbf{8 5 \%}$ & $\mathbf{8 8 \%}$ & $\mathbf{6 9 \%}$ \\
\hline
\end{tabular}

Fonte: FAO, 2017.

A União Europeia ocupa um lugar de grande importância tanto na produção, como nas exportações mundiais de vinho, com destaque cinco países que se encontram entre os dez maiores produtores mundiais: Itália, Espanha, França, Alemanha e Portugal, que juntos dominaram em 2014 cerca de $63 \%$ das exportações mundiais (Tabela 2).
O mundo do vinho está cada vez mais competitivo. Até o ano de 2007, os vinhos franceses apresentavam um market share de $70 \%$ do mercado inglês. Em 2011, este índice caiu para $30 \%$. A Grã-Bretanha foi tomada por rótulos de países do Novo Mundo do Vinho: Argentina, Chile, Austrália, Nova Zelândia e até do Brasil (WINE OF BRAZIL, 2011). 
(MELO et al., 2017)

Tabela 2 - Exportação Mundial de Vinho em toneladas

\begin{tabular}{|l|r|r|r|r|r|}
\hline \multicolumn{1}{|c|}{ Países } & \multicolumn{1}{c|}{$\mathbf{2 0 0 6}$} & \multicolumn{1}{c|}{$\mathbf{2 0 0 8}$} & \multicolumn{1}{c|}{$\mathbf{2 0 1 0}$} & \multicolumn{1}{c|}{$\mathbf{2 0 1 2}$} & \multicolumn{1}{c|}{$\mathbf{2 0 1 4} * *$} \\
\hline Espanha* & 1.336 .762 & 1.698 .171 & 1.771 .386 & 2.095 .279 & 2.260 .000 \\
\hline Itália* & 1.793 .152 & 1.733 .889 & 2.192 .254 & 2.104 .949 & 2.054 .000 \\
\hline França* & 1.461 .663 & 1.345 .513 & 1.411 .363 & 1.565 .416 & 1.438 .700 \\
\hline Chile & 471.557 & 581.685 & 729.938 & 747.364 & 799.900 \\
\hline Austrália & 762.278 & 701.050 & 799.465 & 734.736 & 730.010 \\
\hline África do Sul & 272.386 & 432.789 & 392.284 & 412.817 & 479.900 \\
\hline USA & 368.868 & 463.817 & 400.854 & 400.705 & 404.500 \\
\hline Alemanha* & 315.962 & 358.090 & 385.199 & 395.331 & 386.300 \\
\hline Portugal* & 286.103 & 286.549 & 252.850 & 333.655 & 285.400 \\
\hline Argentina & 301.810 & 430.485 & 280.996 & 372.641 & 262.600 \\
\hline Total & $\mathbf{7 . 3 7 0 . 5 4 1}$ & $\mathbf{8 . 0 3 2 . 0 3 8}$ & $\mathbf{8 . 6 1 6 . 5 8 9}$ & $\mathbf{1 0 . 3 9 6 . 2 6 6}$ & $\mathbf{1 0 . 2 4 0 . 0 0 0}$ \\
\hline *Participação dos 5 Países da EU & $70 \%$ & $68 \%$ & $70 \%$ & $62 \%$ & $63 \%$ \\
\hline
\end{tabular}

Fonte: FAO, 2012; FAO 2017; **ITALIAN WINE, 2017

Em relação ao consumo mundial de vinho (Tabela 3), observamos que em 2016 os EUA, se mantêm na liderança com um consumo interno de 31,8 milhões de hectolitros, com um mercado em permanente expansão. Logo após vem, em segundo, a França (27 milhões de hectolitros), que até a década de 2000 era o maior consumidor. Em terceiro temos a Itália com 22,5 milhões de hectolitros, país em que também apresentou um pequeno aumento no consumo.

Observa-se que os países do velho continente apresentam uma relativa estabilidade no consumo de vinhos. Já em 2016, segundo a OIV (2017), o consumo anual foi de 242 milhões de hectolitros. Tomando como base a Tabela 3, houve um incremento negativo no consumo entre 2012 e 2016 na ordem de $-0,82 \%$.

Tabela 3 - Consumo Mundial de Vinhos em milhões de hectolitros.

\begin{tabular}{|c|r|r|r|r|r|}
\hline Países & \multicolumn{1}{|c|}{$\mathbf{2 0 1 2}$} & \multicolumn{1}{|c|}{$\mathbf{2 0 1 3}$} & \multicolumn{1}{|c|}{$\mathbf{2 0 1 4}$} & \multicolumn{1}{|c|}{$\mathbf{2 0 1 5}$} & \multicolumn{1}{c|}{$\mathbf{2 0 1 6}$} \\
\hline EUA & 30,00 & 30,20 & 30,40 & 31,00 & 31,80 \\
\hline França & 28,00 & 27,80 & 27,50 & 27,20 & 27,00 \\
\hline Itália & 21,60 & 20,80 & 19,50 & 21,40 & 22,50 \\
\hline Alemanha & 20,30 & 20,40 & 20,20 & 20,60 & 20,20 \\
\hline China & 17,10 & 16,50 & 15,50 & 16,20 & 17,30 \\
\hline Inglaterra & 12,80 & 12,70 & 12,60 & 12,70 & 12,90 \\
\hline Espanha & 9,90 & 9,80 & 9,90 & 10,00 & 9,90 \\
\hline Argentina & 10,10 & 10,40 & 9,90 & 10,30 & 9,40 \\
\hline Rússia & 11,30 & 10,40 & 9,60 & 9,30 & 9,30 \\
\hline Austrália & 5,40 & 5,40 & 5,40 & 5,30 & 5,40 \\
\hline Canadá & 4,90 & 4,90 & 4,70 & 4,90 & 5,00 \\
\hline Portugal & 5,00 & 4,80 & 4,70 & 4,80 & 4,80 \\
\hline África do Sul & 3,60 & 3,70 & 4,00 & 4,20 & 4,40 \\
\hline Romênia & 4,30 & 4,60 & 4,70 & 3,90 & 3,80 \\
\hline Japão & 3,10 & 3,40 & 3,50 & 3,50 & 3,50 \\
\hline Demais Países & 56,2 & 57,2 & 57,9 & 55,7 & 54,8 \\
\hline Mundo & $\mathbf{2 4 4}$ & $\mathbf{2 4 3}$ & $\mathbf{2 4 0}$ & $\mathbf{2 4 1}$ & $\mathbf{2 4 2}$ \\
\hline
\end{tabular}

Fonte: OIV, 2017. 
(MELO et al., 2017)

De acordo com o International Wine and Spirits Record - IWSR (2009), se confirmou o aumento do consumo de vinho em 2013, alcançando um volume de 243 milhões de hectolitros, passando os EUA a ser o principal mercado do vinho. Porém a partir desse patamar, houve, uma pequena retração no mercado $(-0,82 \%)$ no período entre 2012 e 2016, considerando um ajuste na demanda.

\section{b. Indicações Geográficas e o Agronegócio Vinícola}

Para Lockshin e Rhodus (1993), no processo de escolha, os consumidores de vinho utilizam características extrínsecas, as quais podem ser alteradas sem mudar o produto e as suas características intrínsecas, que estão diretamente relacionadas ao produto. Portanto, a percepção da qualidade dos vinhos é baseada tanto em características intrínsecas, como o método de processamento, a variedade da uva, a quantidade de álcool e o estilo do vinho (reserva, de mesa), quanto em características extrínsecas, como preço, embalagem, rotulagem e marca. A marca é mais usada para identificar um vinho no Novo Mundo do que na Europa, onde os vinhos são identificados por região ou vinhedo (LOCKSHIN, 2001).

Considerando que o mercado vinícola possui um elevado grau de competitividade em um mercado altamente dinâmico, uma das formas para atingir amplos mercados, é a de diferenciação, por meio da qual as empresas buscam aumentar a percepção de valor de seus produtos, adotando estratégias que passam pelo desenvolvimento de sinais de qualidade particulares ou coletivas formais ou ainda informais que levam a diferenciação dos produtos.

O avanço do comércio de alimentos trouxe também seus problemas, revelando uma crescente preocupação quanto à origem e processo dos alimentos por parte dos consumidores, levando os produtores a desenvolver uma série de selos de qualidade, sinalizando pontos de interesse destes.
Lembramos que a era do "Alimento Seguro" marca uma nova fase do sistema de produção agrícola. Segundo Panza et al., (2006) o conceito, além de garantir que o produto não tem contaminação físico-química e biológica, se estende também às questões ambientais e sociais ao longo de toda a cadeia de comercialização, até o consumidor final. À luz da fase do alimento seguro, o registro de Indicação Geográfica é um instrumento que transmite confiança ao consumidor, no que diz respeito à origem e a qualidade do produto.

Desse modo, a proximidade entre produtor e consumidor, através da estratégia de diferenciação, tem se apresentado um fator competitivo, em que os selos distintivos de qualidade têm reduzido às incertezas, no âmbito dos consumidores, quanto à qualidade dos produtos como no caso da Indicação Geográfica. Assim, as Indicações Geográficas são um exemplo que confere uma sinalização de qualidade aos produtos agroalimentares, mediante a diferenciação e a vinculação do produto aos atributos do território, como tradição, cultura, edafoclimatologia e o saber fazer das pessoas (GLASS e CASTRO, 2009).

Podemos mencionar a relevância das Indicações Geográficas vinculada ao consumo de produtos de qualidade, o qual está alicerçado, inicialmente, à tradição e à reputação construída ao longo do tempo na Europa em torno de produtos com origem conhecida, em cujo cenário a França se destaca (SOUZA, 2006). Segundo Glass e Castro (2009), os 476 vinhos franceses registrados com IG's até o final de 2006, geraram 14 bilhões de euros anuais, o que equivale a aproximadamente $80 \%$ do valor da produção vinícola do país, ocupando apenas $57 \%$ da área destinada a produção Vitis vinifera.

Portanto, conforme apresentado na Figura 1, até o ano de 2011 os Estados Unidos lideravam o ranking das IG's no setor vinícola mundial, com 697 no total, em segundo a

\footnotetext{
1 Alimento seguro é, portanto, um produto que não apresenta riscos à saúde humana, não degrada o meio ambiente e que promove a melhoria da qualidade de vida das pessoas relacionadas à cadeia de produção (FAO, 2011).
} 
(MELO et al., 2017)

França, com 610 e em seguida a Itália com 532.

Figura 1 - Indicações Geográficas nos 10 maiores exportadores mundiais de vinho.

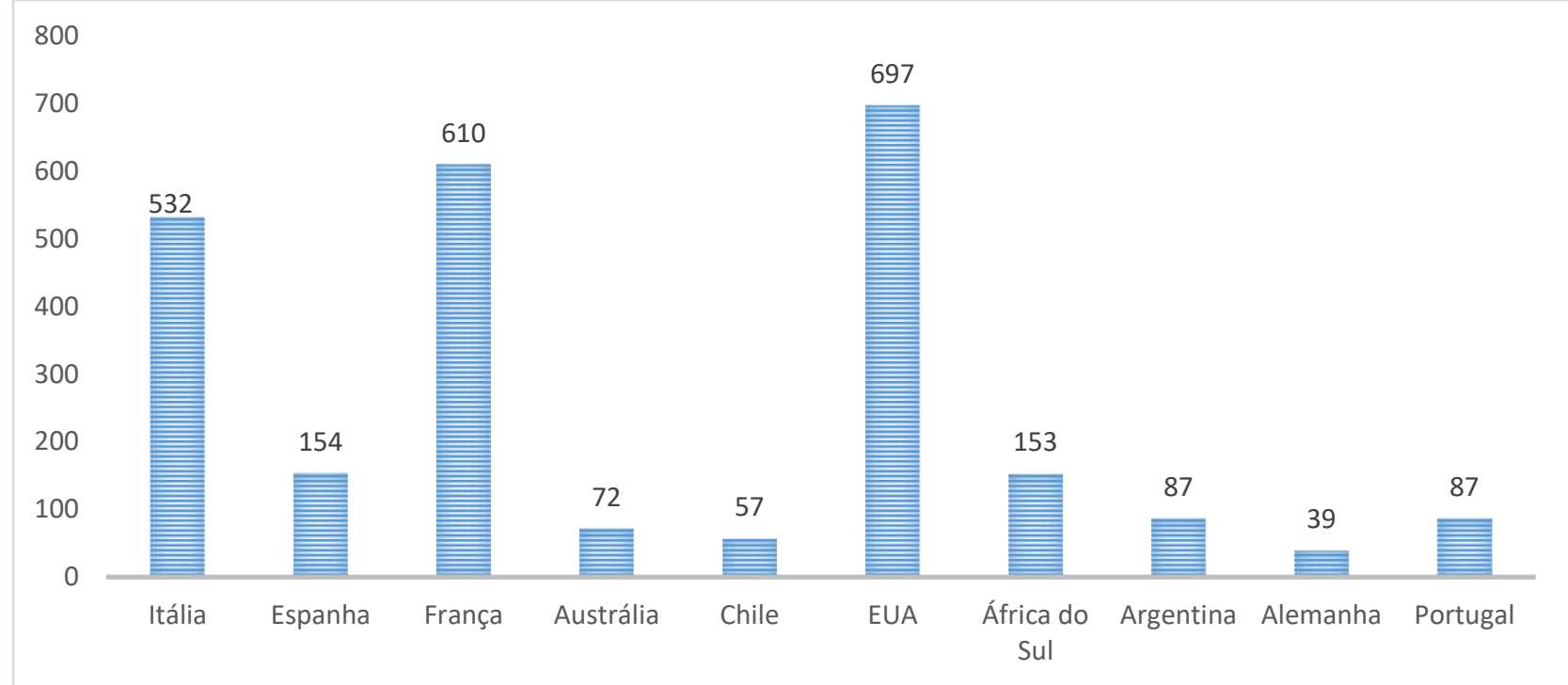

Fonte: elaborado pelos autores baseados em dados da Comissão Européia E-Bachus. Disponível em: HTTP://ec.europa.eu/agriculture/markets/wine/e-bachus. Acessado em: 15.07.2011 e Instituto Nacional de vitivinicultura em: www.inv.gov.ar/pdf/ig.pdf acessado em: 15.07.2011.

\section{c. A Produção de Vinhos na União Europeia na atualidade}

Segundo dados da COMISSÃO EUROPEIA (2017), em 2016, a produção de vinhos na União Europeia foi de 17,3 milhões de toneladas, o que equivale a aproximadamente $60 \%$ da produção mundial. Esses números dão a dimensão da importância da União Europeia no agronegócio mundial do vinho.

Ainda segundo a COMISSÃO EUROPEIA (2017), mostra que a produção de vinho da União Europeia atingirá em 2017 uma espectativa de produção $4,3 \%$ menor, ou seja, um total de 16,6 milhões de toneladas.

Desse total, 10,3 milhões de toneladas de vinho são vinculados a indicações geográficas, o que corresponde a $62 \%$ do total.

\section{d. As Indicações Geográficas na União Europeia}

I. A regulamentação que rege as IGs na União Europeia

A regulamentação técnica das indicações geográficas provavelmente surgiu na Europa onde era de costume designar o nome dos produtos com o seu local de fabricação ou de sua colheita, a exemplo, do Queijo Roquefort, que tem notoriedade desde o século XIV, usando o nome de seu local de origem, assim como, as Ordenanças Municipais de Ribadavia, que em 1579 já se preocupavam em proteger os vinhos produzidos na Galícia, especificamente na Comarca do Ribeiro.

Nesse contexto, nasceram diversas apelações de origem francesas no setor agroalimentar, como o queijo Roquefort, em 1925. Com o fracasso das duas leis para resolver as crises vinícolas, a Apelação de Origem Controlada foi instaurada e regulamentada em 1935, quando foram criados o Instituto Nacional de Apelações de Origem (INAO) e o Comitê Nacional para Vinhos e Aguardentes. O sucesso econômico dos "vinhos e aguardentes" com AOC incitou a estender as Apelações de Origens Controladas (AOCs) a todos os produtos alimentares por intermédio de uma lei de 1990, que criou, no INAO, os comitês nacionais de "Produtos Lácteos" e de "Produtos Agroalimentares". Na França, considera-se Apelação de Origem Controlada o nome de uma região ou local determinado que serve para designar um produto agrícola ou alimentício originário dessa 
(MELO et al., 2017)

área ou lugar específico cujas qualidades ou características se devam essencialmente ao meio geográfico específico, devido a fatores naturais ou humanos, e que sua produção, elaboração ou transformação ocorram exclusivamente na região delimitada. Já a Indicação Geográfica Protegida (IGP) diferencia-se da AOC por possibilitar que alguma das fases de produção possa ocorrer fora da área geográfica delimitada. Em julho de 1992, a Comunidade Europeia estabeleceu um sistema de proteção para nomes geográficos, envolvendo duas noções de proteção: Denominação de Origem e Indicação Geográfica. Este regramento foi aperfeiçoado recentemente, pelo Regulamento (CE) $n^{\circ}$ 510/2006 do Conselho Europeu, datado de 20 de março de 2006 (KAKUTA et al., 2006).

A União Europeia estabelece regras comuns sobre denominações de origem e indicações geográficas protegidas, às menções tradicionais, à rotulagem e apresentação de determinados produtos. O Regulamento CE $\mathrm{n}^{\circ}$ 607/2009 da Comissão, de 14 de Julho de 2009 estabelece certas normas de execução do Regulamento CE no 479/2008 do Conselho no que diz respeito à denominação de origem e indicações geográficas, termos tradicionais, à rotulagem e apresentação de determinados produtos (UE, 2009).

A denominação de origem protegida (DOP) designa o nome de um produto cuja produção deve ter ocorrido em uma determinada área geográfica com uma reconhecida experiência e constatados. Qualquer produto com DOP deve ser feito exclusivamente a partir de uvas cultivadas na área geográfica considerada.

A indicação geográfica protegida (IGP) designa o nome de um produto que tem uma qualidade, reputação ou outras características atribuíveis a uma determinada área geográfica. Qualquer produto com um IGP deve ser preparado, pelo menos, com $85 \%$ das uvas a partir da área geográfica considerada.

Os termos tradicionais são utilizados para: indicar que o produto está coberto pela DOP ou IGP sob o direito europeu e do direito de um Estado-Membro; designar o método de produção ou de envelhecimento, uma qualidade, cor ou tipo de lugar ou um acontecimento particular ligado à história do produto que recebe uma DOP ou IGP.

Os pedidos de proteção de termos tradicionais são apresentados à Comissão pelas autoridades competentes dos Estados-Membros ou de países terceiros ou organizações vitivinícolas profissionais. Os termos tradicionais constantes no Anexo XII, são protegidos apenas na língua ou categoria de produto vitivinícolas especificado no pedido. Eles são protegidos contra qualquer usurpação (embora o termo protegido seja acompanhado de uma expressão como "estilo", "tipo", "método", "como é produzido", "imitação", "sabor", "como" ou qualquer outra expressão similar) e práticas susceptíveis de enganar os consumidores.

O nome da categoria não é necessário para vinhos cujo rótulo inclua o nome protegido de uma denominação de origem ou indicação geográfica. Os termos "denominação de origem protegida" ou "indicação geográfica protegida" podem ser omitidos se: o rótulo contém um termo tradicional; se o rótulo contém a figura da denominação de origem ou indicação geográfica (em casos excepcionais determinados pela Comissão).

A presença de sulfitos deve ser indicada no rótulo, em conformidade com a Diretiva 2000/13/CE relativa à rotulagem e apresentação dos gêneros alimentícios.

Todas as indicações obrigatórias (exceto o importador e o número de lote) devem aparecer no mesmo campo visual da garrafa de forma clara e visível.

A DOP, IGP ou o termo tradicional aparecem no rótulo na língua ou línguas em que a proteção se aplica. Quando não as DOP, as IGP ou as denominações nacionais específicas não se escrevem em um alfabeto latino, o nome pode aparecer em uma ou mais línguas oficiais da União Europeia.

\section{Os números das Indicações Geográficas na União Europeia}

Diante de toda uma história voltada para a proteção de produtos de origem europeia, era de se esperar que o número de indicações 
(MELO et al., 2017)

geográficas na União Europeia fosse expressivo no agronegócio mundial do vinho. A Figura 2 mostra a dimensão e importância que as indicações geográficas têm nesses países, atualmente existem registradas nas diversas formas de indicações geográficas 3.048 proteções para vinho na União Europeia. Dessas, 1.991 são de países da UE e 1.127 de outros países. Das 1.991 proteções para vinho dos países da União Europeia, 587 estão na forma de Indicação Geográfica Protegida (IGP) e 1.334 na forma de Denominação de Origem Protegida (DOP). Para os outros países que não fazem parte da UE, existem 696 na forma de Nome de Origem Protegido, 429 na forma de Indicação Geográfica e apenas 2 como Denominação de origem protegida (DOP).

Figura 2 - Todas as Indicações Geográficas de Vinhos na União Europeia.

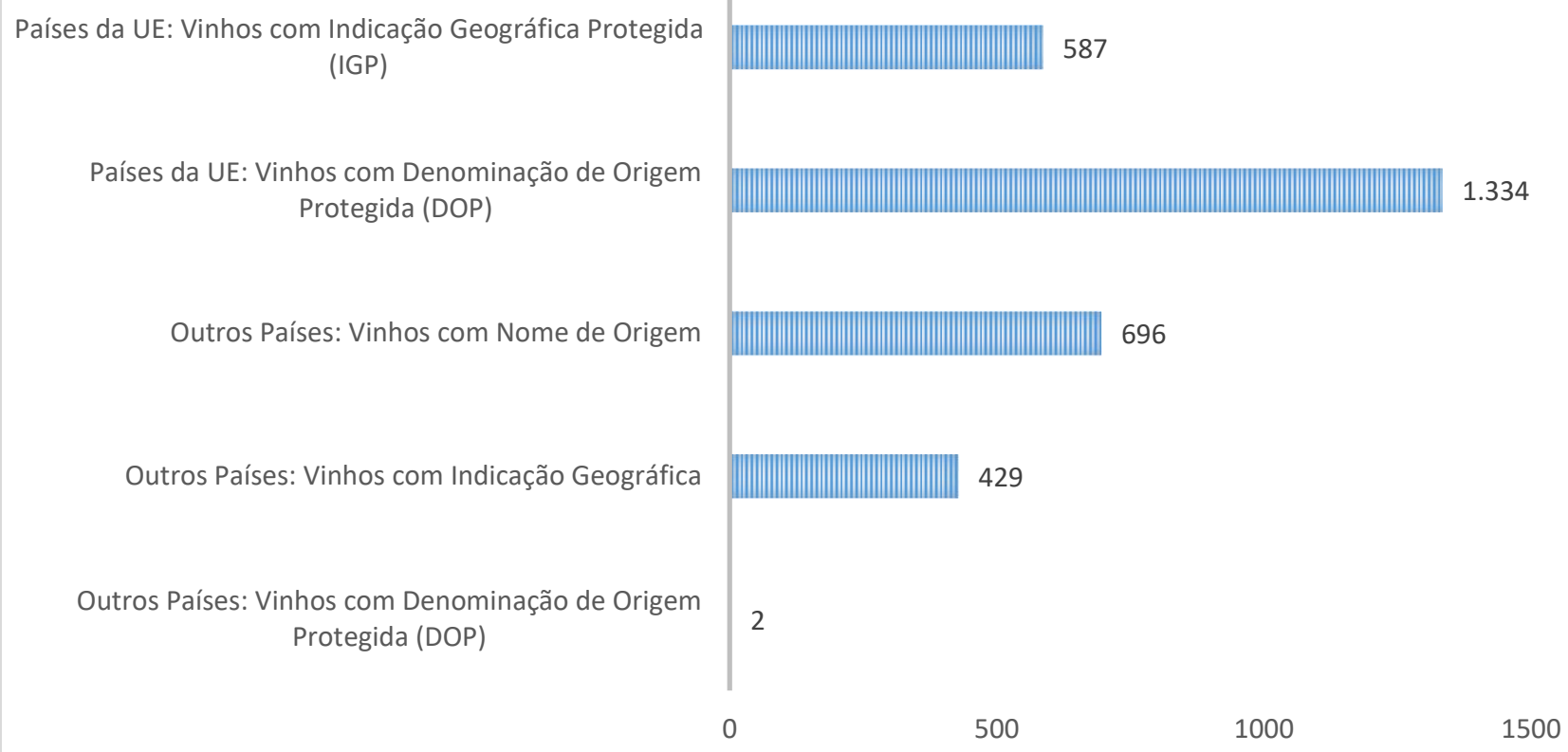

Fonte: EBACCUS, 2012.

Pelos números apresentados, observa-se a importância que é dada para as proteções nas diversas formas de indicações geográficas, pois $63 \%$ das proteções totais são para vinhos produzidos na UE, porém existe uma abertura para proteção de vinhos de países terceiros, as quais respondem por $37 \%$ do total das proteções. Esse fenômeno pode estar associado ao fato da forte entrada de vinhos de países como Estados Unidos da América, Argentina, Chile, Austrália, Nova Zelândia, África do Sul e até do Brasil, nesse continente, principalmente nos países com menos expressão na produção.

Quando analisamos proteções para vinho dentro União Europeia por parte dos seus países membros, verificamos que a maioria são para as Denominações de Origem Protegidas (DOP), essas respondem por $67 \%$ do total das proteções, ou seja, 1.334 proteções (Figura 3), como era de se esperar, os quarto maiores produtores de vinho Itália (412), França (450), Espanha (111) e Portugal (69), que também estão entre os dez maiores produtores mundiais, responde juntos por $49 \%$ dessas proteções. Um destaque a ser feito é para a Romênia (52), Bulgária (52) e Eslováquia (43), países que são membros mais recentes da UE, mas que já mostram sua força na produção de vinhos reconhecidos e protegidos. 
(MELO et al., 2017)

Figura 3 - Vinhos com Denominação de Origem Protegida (DOP) na União Europeia - países da EU.

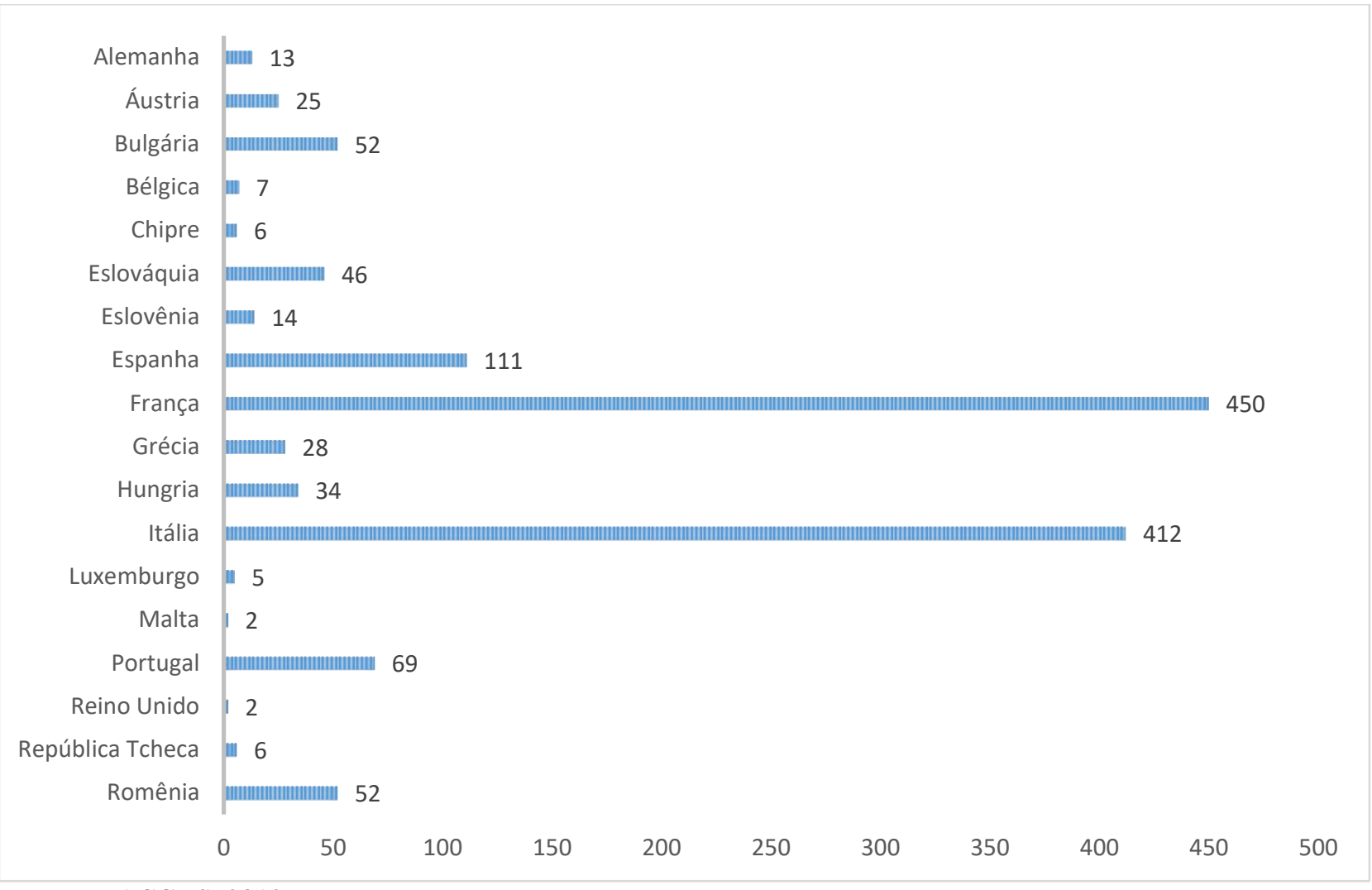

Fonte: EBACCUS, 2012.

Observa-se para os vinhos da União Europeia, a predominância das denominações de origem protegidas (DOP) em relação às indicações geográficas protegidas (IGP), isso mostra o grau de desenvolvimento em que está o processo de proteção para vinhos nos países do bloco. Enquanto que em outros países que estão buscando proteger seus produtos mais recentemente, a exemplo do Brasil, a predominância é das indicações de procedência.

As Indicações Geográficas Protegidas (IGP) de países membros dentro da União Europeia são de 587, ou seja, 33\% do total de todas as proteções, mesmo sendo em menor número, não são de menor importância, pois quando comparadas a países terceiros são altamente expressivas. A Figura 4 apresenta a distribuição das IGP's.
Observa-se que o comportamento em relação distribuição dessas proteções é similar a das DOPs, ou seja, os quatro maiores produtores, Itália (120), França (160), Espanha (43) e Portugal (18), respondem juntos por $58 \%$ do total das IGP's. Um destaque deve ser feito para o Reino Unido (43) e Alemanha (26) que apresentam números expressivos de proteções na forma de IGP.

Vinhos mais recentemente reconhecidos no mercado de países com menos tradição na produção de vinhos, parecem buscar de início a proteção na forma de IGP's, dado o fato de haver menos requisitos para concessão das mesmas quando comparadas com as DOP's, isso mostra que além dos países tradicionais na produção de vinhos, surgem novos países nesse cenário. 
(MELO et al., 2017)

Figura 4 - Vinhos com Indicação Geográfica Protegida (IGP) na União Europeia - países da EU.

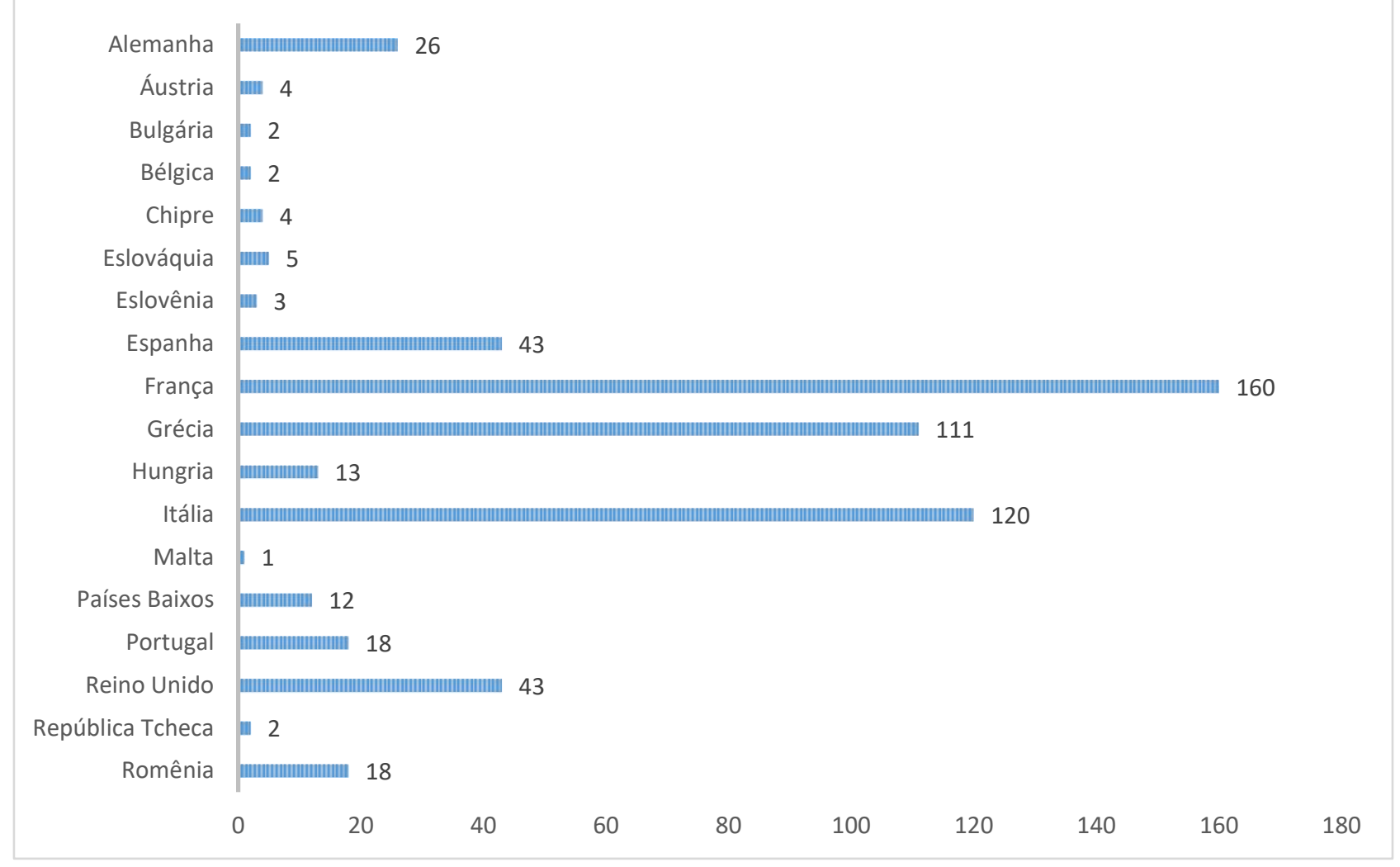

Fonte: EBACCUS, 2012.

\section{Conclusões}

As Indicações Geográficas são uma forma coletiva de proteção e promoção mercadológica e têm o objetivo de destacar lugares, pessoas e produtos considerando características peculiares do território, quase intransferíveis, tais como a cultura.

No contexto de promoção mercadológica, o estudo apontou que os dez maiores países exportadores mundiais de vinhos apresentavam $82,06 \%$ do total de 3.032 IG's identificadas. A pesquisa também revelou que países pertencentes ao "novo mundo do vinho" tais como: Austrália, África do Sul, EUA e Chile, adotaram como diferencial competitivo as IG's, as quais tiveram origem nos países tradicionais tidos como "o velho mundo do vinho", com destaque para: França, Itália, Espanha e Portugal.

Observou-se que o número de Indicações Geográficas para vinho registradas até 2011 na União Europeia era de 3.048, onde com origem nesta, havia 1.991, o que correspondia a $65,3 \%$ do total de registros de IG's. Desse total, 1.334 (67\%) eram DOP e 587
(33\%) eram IGP, sendo que ambas se concentram na França, Itália, Espanha e Portugal, o que sugererelação entre o uso de inovações por meio de signos distintivos e liderança nas exportações.

Portanto, as IG's têm sido uma ferramenta inovadora e fundamental na redução da assimetria de informação e aproximação entre produtores e consumidores de vinhos na União Europeia. Desta forma, como o caso da França, além do crescimento da produção, também se verifica um aumento de consumo e confiança da procedência e qualidade dos produtos vitivinícolas.

Depreende-se desse estudo a necessidade de compreender melhor os fatores de cooperação que promovem essa dinâmica, e verificar a possibilidade de aplicá-los a realidade brasielira no segmento vitivinícola. Para isso será preciso melhor organizar as instucionais nacionais que atuam com dados sobre o mercado vitivinícola.

\section{Referências Bibliográficas}


(MELO et al., 2017)

ADDOR, F.; GRAZIOLI, A. Geographical Indications beyond Wines and Spirits. THE JOURNAL OF WORLD INTELLECTUAL PROPERTY. v.5, n.6, p.865-8972, November 2002.

COCCO, G; GAlVÃO, A. P.; SILVA, M. C. Pereira. Desenvolvimento Local e Espaço Público na Terceira Itália: Questões para a Realidade Brasileira. In: Empresários e Empregos nos Novos Territórios Produtivos O caso da Terceira Itália. Rio de Janeiro: DP \& A Coope, P\&D. Wills, p.12-31, 1999. (Org. Cocco, G; Urani, A.; Galvão, A.P).

CASSAROTO FILHO, N; PIRES, L. H. Rede de pequenas e médias empresas e o desenvolvimento regional. São Paulo: Atlas, 1999.

COMISSÃO EUROPÉIA. Disponível em: https://ec.europa.eu/agriculture/wine/statistics_ en. Acesso em 01 mai. 2017.

\section{COMISSÃO EUROPÉIA E-BACHUS.}

Disponível em: http://ec.europa.eu/agriculture/ markets/wine/e-bachus. Acesso em: 15 jul. 2011.

EBACCUS. Indicações geográficas, 2012. Disponível em <http://ec.europa.eu/ agriculture/markets/wine/e-

bacchus/index.cfm? \&language $=\mathrm{PT}>$. Acesso em: 26 Nov. 2012.

EUROPA. E U (2012). Disponível em < http://europa.eu/> . Acesso em 04 Dez. 2012.

FALCÃO, T. F.; REVILLION, J. P. P. A indicação geográfica de vinhos finos segundo a percepção de qualidade de enófilos. Ciência Rural, Santa Maria, v.40, n.2, p.453-458, fev, 2010.

FAO. FAOSTAT, 2012. Disponível em < http://faostat3.fao.org/home/index.html\#DOW NLOAD>. Acesso em 26 Nov. 2012.
FAO. FAOSTAT, 2017. Disponível em < http://www.fao.org/faostat/en/\#home>. Acesso em 01 Mai. 2017.

GLASS, R. F.; CASTRO A.M.G. As indicações geográficas como estratégia mercadológica para vinhos. Texto para discussão 35. EMBRAPA Informação Tecnológica. Brasília: 2009, 113p.

GOLLO, S. S. Inovação e estratégia de cooperação competitiva: estudo de caso da indicação de procedência Vale dos Vinhedos, Serra Gaúcha/RS. 2006. 359 p. Tese (Doutorado em Administração) -Universidade Federal do Rio Grande do Sul, Porto Alegre, 2006.

HUGHES, D. Breaking with tradition: Building partnerships and alliances in the European food industry. London: Wye College Press. 1994.

INTERNATIONAL WINE AND SPIRITS RECORD (IWSR). Disponível em INSTITUTO NACIONAL DE VITIVINICULTURA. Disponível em: http://www.inv.gov.ar/pdf/ig.pdf. Acesso em: 15 Jul. 2011.

ITALIAN WINE CENTRAL. Disponível em $<$ http://italianwinecentral.com/category/3statistics/international/>. Acesso em: 01 Mai. 2017.

KAKUTA, S. M. Indicações geográficas: guia de respostas. / Susana Maria Kakuta, Alessandra Lo Iacono Loureiro de Souza, Fernando Henrique Schwanke, Hulda Oliveira Giesbrecht. - Porto Alegre: SEBRAE/RS, 2006. Disponível em http://www.biblioteca.sebrae.com.br/ bds/BDS.nsf/7B4FAF1836BF6DBE832575CF 0072CEC7/\$File/NT00040FE2.pdf. Acesso em: 29 Nov. 2012.

LLOPIS, G. Y. (Trad. Jorge Tonietto). Denominações de origem e indicações geográficas de produtos vitivinícolas. Bento Gonçalves: Embrapa - Uva e Vinho, 1997, 20p. 
(MELO et al., 2017)

PANZA, S. G. A.; BROTHERHOOD, R.;

LOCKSHIN, L.; QUESTER P.; SPAWTON, T. Segmentation by Involvement or Nationality for Global Retailing: A Cross National Comparative Study of Wine Shopping Behaviours. Journal of Wine Research, Abingdon, v. 12, n. 3, p. 223-236, 2001.

LOCKSHIN, L. S.; RHODUS, W. T. The effect of price and oak flavor on perceived wine quality. International Journal of Wine Marketing, [Surrey], v. 5, n. 2, p. 13-25, 1993.

GRUNERT, K. G. A framework for analyzing innovation in the food sector. CENTRE FOR MARKET SURVEILLANCE, RESEARCH AND STRATEGY FOR THE FOOD SECTOR no. 38 Nov. 1995.

ORGANIZAÇÃO INTERNACIONAL DA VINHA E DO VINHO - OIV. Disponível em: http://www.oiv.int/es/accueil/index.php. Acesso em 15 mai. 2011.

ORGANIZAÇÃO INTERNACIONAL DA VINHA E DO VINHO - OIV. Disponível em: http://www.oiv.int/en/databases-andstatistics/statistics. Acesso em 01 mai. 2017.
ANDREOTTI, A.; REZENDE, C.; BALERONI, F. H.; PAROSCHI, V. H. B. Avaliação das Condições HigiênicoSanitárias Durante a Manipulação dos Alimentos, em um Restaurante Universitário, Antes e Depois do Treinamento dos Manipuladores. São Paulo: ANATEC, 2006.

PINDYCK, R.; RUBINFELD, D. Microeconomia. São Paulo: Prentice Hall, 2002. relational contracting. New York: The Free Press, c 1985. 450 p.

RAPPORTO $2010 \quad$ SULL'ECONOMIA
REGIONALE Romagna - Regione Emilia-Romagna. 2010.208 p. Disponível em: http://www.ucer.camcom.it/comunicazione/ .../ 2010/ProgrammaRapporto2010.pdf. Acesso em: 10 Jun. 2011.

RAPPORTO NAZIONALE SUL SETTORE VITIVINICOLO 2009. Unioncamere EmiliaRomagna - Regione Emilia-Romagna. 2009. 112 p. Disponível em: http://www.unioncamere.gov.it/ download/550.html. Acesso em: 10 Jun. 2011. 